\title{
General integration and regulation of metabolism at the organ level
}

\author{
B Y M. ELIA \\ Dunn Clinical Nutrition Centre, Hills Road, Cambridge CB2 2DH
}

\section{Intégration générale et régulation du métabolisme au niveau des organes}

\begin{abstract}
RÉSUMÉ
C'est un principe général dans le domaine cardio-vasculaire que les modifications des activités métaboliques des tissus, telles que celles qui sont associées à la contraction musculaire, à la lipolyse dans le tissu adipeux ou à l'augmentation de l'activité nerveuse dans certaines parties du cerveau, sont associées avec une augmentation spécifique du flux sanguin vers ces tissus ou certaines parties de ces tissus. Le capillaire est un détecteur métabolique important qui répond à de multiples signaux métaboliques tels que les $\mathrm{K}^{+}$et $\mathrm{H}^{+}$, l'acétyl choline, et les analogues d'adénosine, qui peuvent s'accumuler dans une activité métabolique accrue. Le capillaire est idéalement situé pour détecter les signaux de zones entières de tissu, et répond en produisant des signaux électrotoniques qui produisent ensuite une réponse des artérioles à distance, ce qui est essentiel pour le contrôle du flux sanguin. Bien que l'activité métabolique influence le flux sanguin dans les tissus, une modification du flux sanguin dans les tissus peut elle-même influencer le métabolisme. En général, les substrats qui ont une captation fractionnelle élevée dans les tissus (ou un relargage fractionnel élevé), sont très fortement influencés par les modifications du flux sanguin. Les modifications de la concentration circulante des métabolites influencent également le métabolisme des tissus. Cela signifie qu'un tissu peut en influencer un autre en contrôlant l'apport des substrats, comme l'apport de glucose et de corps cétoniques (foie) ou de lipides non estérifiés (tissu adipeux). Etant donné que le contenu énergétique combiné de ces substrats dans tout le sang varie peu dans de nombreuses situations physiopathologiques telles que l'alimentation et le jeûne, alors que leurs proportions respectives changent substantiellement, il y a un potentiel considérable de compétition entre les substrats pour le métabolisme de l'oxydation. L'importance de cette compétition dépend dans une certaine mesure de l'activité des systèmes d'enzymes dans les tissus pour métaboliser les substrats spécifiques. Les modifications du point d'équilibre de captation ou de relargage des métabolites par les tissus peuvent être influencées par des substances bioactives telles que les hormones et les cytokines, qui fournissent un autre mécanisme important pour la régulation métabolique dans l'alimentation et le jeûne, l'exercice et le repos, et dans la maladie. Nous pouvons conclure que les concentrations dans le sang, les nerfs, les hormones et les substrats sont intimement liées au contrôle du métabolisme, mais qu'il manque encore bien des détails dans les processus qui intègrent et lient le métabolisme de la cellule au métabolisme des tissus au métabolisme du corps tout entier.
\end{abstract}


Early in evolution, cellular specialization led to the formation of discrete organs and tissues, resulting in specific body functions being carried out more efficiently. However, this development could not have become successful without an integrated system of communication that could coordinate the metabolic processes in the various tissues of the body during physiological events such as feeding and fasting, exercise and rest. What triggers the liver to increase its output of glucose severalfold, and adipose tissue its output of non-esterified fatty acids (NEFA) when the requirement for nutrients is high, as for example during exercise? In contrast, what directs the liver to reduce its glucose output, and adipose tissue its output of NEFA when the availability of nutrients is high, as for example after a meal? What are the signals that operate between tissues?

With processes of such fundamental importance and complexity, it is not surprising that nature employs not one method of control but multiple methods, and not one method of communication but multiple communication systems.

Some methods of communication are fast (e.g. those involving nerves) whilst others are slower (e.g. those involving the circulation). The signals may involve small quantities of regulatory substances (e.g. hormones) or large quantities (e.g. metabolites). Some signals have major effects on the metabolism of some tissues and little or no effect on other tissues. This may depend on whether tissues have receptors, to respond to the signals, or the 'machinery' to transport and metabolize fuels (e.g. the brain does not readily oxidize NEFA and erythrocytes, which lack mitochondria, do not oxidize glucose or NEFA).

In order to obtain a clearer understanding of inter-organ metabolic regulation it is necessary to identify the primary or rate-limiting step that determines metabolic flux across a tissue, or more than one when a sequence of metabolic events in a pathway span across more than one tissue. This information has not always been easy to establish, for at least three reasons. First, quantitative information about rates of exchange of metabolites across tissues in vivo in response to specific stimuli or signals may be technically difficult to establish, especially when fluxes across several tissues are being assessed simultaneously. Second, the rate-limiting or flux-generating step may vary in different circumstances (see p. 224). Third, it is not only important to identify the rate-limiting step in the metabolism of an individual tissue but also to identify which tissue or which events within tissues become rate limiting for metabolic pathways within the body as a whole.

\section{BLOOD FLOW}

In some circumstances blood flow can be the primary determinant or the rate-limiting factor for the metabolism and function of tissues. The haemodynamic aspects of metabolic regulation have received little attention and, therefore, some examples of their importance are given, before the control processes are discussed.

The clinician has little doubt that, although in some individuals exercise may be limited by the intrinsic properties of the muscle itself (e.g. in patients with a myopathy), in others it is limited by blood flow to the legs (e.g. in patients with arteriosclerosis and intermittent claudication of the leg), and in others it is limited by blood flow to a variety of other tissues (e.g. to the heart in patients with myocardial angina, intestine in patients with intestinal angina). The impaired blood flow not only limits the function of the tissue it supplies, but also the metabolism and function of the body as a whole. 
The physiologist and biochemist also recognize the importance of blood flow in the control of tissue function and inter-organ flux of nutrients. For example, the fractional extraction of $\mathrm{O}_{2}$ across normal resting muscle is about one-third, which means that if blood flow to muscle did not increase during exercise, the maximum $\mathrm{O}_{2}$ consumption of muscle could only treble. Since the $\mathrm{O}_{2}$ consumption of muscle can increase severalfold more than this, it is obvious that this change can only be made possible by a considerable increase in blood flow to muscle. For example, under resting conditions the blood flow to muscle is only about $20-30 \mathrm{ml} / \mathrm{kg}$ muscle per min, but under maximal or near maximal muscular activity it can increase 100-fold as shown in a variety of mammals (Laughlin, 1987) including man (e.g. Andersen \& Saltin, 1986; Rowell et al. 1986; Laughlin, 1987). It has long been argued whether the maximum $\mathrm{O}_{2}$ consumption of muscle depends on the properties of the muscle itself or the blood flow to the muscle. The two are, of course, intimately linked over a wide range of muscular activity (e.g. Donald et al. 1957) and the problem is to explain how changes in blood flow are coupled to metabolism.

Perfusion not only affects the metabolism of exercising muscle but it is likely that it also affects the metabolism of resting muscle of both animals and man. The studies of Schultz et al. (1977) involving the perfused resting hindlimb (whilst connected to the body of the rat), clearly demonstrated that the uptake of glucose was linearly related to glucose delivery, over a wide range of glucose delivery. When perfusate flow was held constant while glucose concentrations increased, glucose uptake increased. When perfusate flow increased and glucose concentration held constant, glucose uptake also increased.

The importance of blood flow in regulating muscle metabolism is also emphasized by recent studies in man. For example, Baron et al. (1994) concluded that blood flow to muscle independently modulates insulin-mediated glucose uptake. Here the hyperinsulinaemic-euglycaemic clamp and leg balance techniques were used to measure glucose uptake by the leg of young healthy lean men both before and after a 2-3-fold increase in leg blood flow induced by metacholine. The metacholine treatment superimposed on a low-dose insulin infusion $\left(15 \mathrm{mU} / \mathrm{m}^{2}\right.$ per min achieving circulating insulin concentrations of approximately $23 \mu \mathrm{U} / \mathrm{ml}$, whilst euglycaemia was maintained) increased leg glucose uptake by a mean of $116 \%$, and superimposed on a high-dose insulin infusion $\left(300 \mathrm{mU} / \mathrm{m}^{2}\right.$ per min, achieving circulating insulin concentrations of approximately $950 \mu \mathrm{U} / \mathrm{ml}$ ) it produced a mean increase in leg glucose uptake of $47 \%$. The implications of such findings, assuming that metacholine predominantly increased blood flow to the muscular rather than non-muscular limb tissues, is that muscle perfusion can affect insulin sensitivity and glucose tolerance. An impaired flow would favour insulin resistance or glucose intolerance. The effect of insulin itself on limb blood flow has been controversial; some reports suggest it has no effect on limb blood flow and others suggest that it produces a substantial increase. In one recent study insulin was reported to increase limb blood flow 2-fold in a dose-dependent manner, with a physiological $50 \%$ effective concentration of $36 \mu \mathrm{U} / \mathrm{ml}$ (Laakso et al. 1990). The authors proposed that the haemodynamic effect could account for up to $40 \%$ of insulin's action to stimulate glucose uptake by increasing glucose delivery via capillary recruitment. Another recent study reported that the insulin-induced changes in muscle blood flow were specific to muscle, and were strongly related to changes in cardiac output. These changes were attenuated in obese insulin-resistant subjects (Baron \& Brechtel, 1993).

The control of tissue metabolism by variations in tissue perfusion rates has not only 
been of interest to biochemists and physiologists but also to pharmacologists, who are concerned about the hepatic and renal clearance of drugs. A physiological approach may be used to predict the relationship between clearance and hepatic blood flow for perfusion-limited elimination assuming a first-order process. The clearance of drugs or metabolites with a high extraction ratio at physiological perfusion rates (e.g. galactose or indocyanide green which have been used to measure hepatic blood flow) are affected to a much greater extent by changes in blood flow than drugs or metabolites with a low extraction ratio (Wilkinson \& Shand, 1975). To some extent these principles apply to the removal of substances across various other tissues.

Blood flow may not only limit or control the uptake of metabolites by a tissue, but also their release, e.g. the release of NEFA from adipose tissue, especially when lipolysis is active. NEFA are not water-soluble and are carried in the circulation predominantly by albumin which has two to three high-affinity binding sites, and a number of other lower-affinity binding sites. Since the molecular weight of albumin is about 65000 , this means that when its circulating concentration is $40 \mathrm{~g} / \mathrm{l}$, the high-affinity sites will bind $1230-1850 \mu \mathrm{mol}$ NEFA/l plasma. When the high-affinity binding sites are saturated or nearly saturated, either as a result of high lipolytic activity or a low perfusion rate, an increase in blood flow (albumin supply) can substantially increase the rate at which NEFA leave adipose tissue. Without this increase in blood flow NEFA accumulate in adipose tissue and re-esterify, as shown by perfused adipose tissue preparations (Bulow \& Madsen, 1981; Madsen et al. 1986). It makes physiological sense, therefore, that adipose-tissue blood flow increases in situations associated with a high rate of lipolysis, e.g. starvation (a 2-fold increase has been reported after $4 \mathrm{~d}$ starvation in obese women), exercise (a 3-fold increase has been reported during 50\% $V_{\mathrm{O}_{2} \text { max }}$; Bulow \& Madsen, 1976) and administration of hormones such as noradrenaline which stimulates the release of NEFA from adipose tissue (a 2-3-fold increase in blood flow has been reported after infusion of noradrenaline at a rate of $0.42 \mathrm{nmol} / \mathrm{kg}$ per min to healthy subjects). In this noradrenaline study, NEFA were measured not only in the arterial blood but also in venous blood draining subcutaneous adipose tissue (Table 1). It can be seen that without an increase in blood flow the same rate of NEFA release would have been achieved only if the venous plasma concentration of NEFA was over 3-4 mmol NEFA/l (Haddy \& Scott, 1975), which is more than can be bound by high-affinity binding sites on albumin. Presumably the effect of noradrenaline to increase adipose tissue blood flow was important in causing the marked increase in the release of NEFA.

Table 1. Effect of noradrenaline on blood flow and the concentration of non-esterified fatty acids (NEFA; $\mu$ molll) in arterial and venous blood draining subcutaneous abdominal adipose tissue (Data from Kurpad et al. 1994)

(Mean values with their standard errors)

\begin{tabular}{|c|c|c|c|c|c|c|c|c|}
\hline \multirow[t]{2}{*}{$\begin{array}{l}\text { Period after administration of } \\
\text { noradrenaline }(\mathrm{min}) \ldots\end{array}$} & \multicolumn{2}{|c|}{0} & \multicolumn{2}{|c|}{30} & \multicolumn{2}{|c|}{50} & \multicolumn{2}{|c|}{60} \\
\hline & Mean & $\mathrm{SE}$ & Mean & SE & Mean & SE & Mean & $\mathrm{SE}$ \\
\hline \multicolumn{9}{|l|}{ NEFA concentration $(\mu \mathrm{mol} / \mathrm{l})$} \\
\hline Arterial blood & 350 & 194 & 1445 & 222 & 1333 & 211 & 1166 & 187 \\
\hline Subcutaneous abdominal vein & 996 & 184 & 2675 & 226 & 2322 & 338 & 2285 & 335 \\
\hline Blood flow (mg/kg tissue per min) & 25 & 5 & 57 & $7 \cdot 7$ & 64 & 6 & 64 & 7 \\
\hline
\end{tabular}


Other hormones, such as antidiuretic hormone, may limit the release of NEFA by adipose tissue in vivo by predominantly reducing blood flow to this tissue. Rofe \& Williamson (1983) investigated the cause of suppressed ketogenesis in rats given ADH, and concluded it was due to a flow-dependent reduction in the release of NEFA which are substrates for ketone production in the liver. A change in the sensitivity of adipocytes to lipolytic agents was not observed. Blood flow to adipose tissue in vivo may also limit the release of NEFA during haemorrhage in the dog (Kovach et al. 1970) and possibly after injury in man. Although there is little direct information about blood flow and release of NEFA from adipose tissue after human injury, it is well known that the circulating NEFA concentration is low compared with the turnover of NEFA. One possible explanation for this is that blood flow to adipose tissue is limiting the release of NEFA, and that the low NEFA concentration in the systemic circulation, which occurs because of the high demand for NEFA by the tissues of the body, favours release of NEFA by increasing the availability of unoccupied binding sites on albumin. A flow limitation of NEFA release has also been implicated during exercise in man (Hodgetts et al. 1991). Although blood flow to adipose tissue increases during exercise in man, it may still limit the release of NEFA, because lipolysis is particularly active and this saturates or nearly saturates the high-affinity albumin binding sites with NEFA.

\section{MATCHING BLOOD FLOW TO METABOLIC ACTIVITY OF TISSUES}

A general cardiovascular principle is that an increase in the metabolic activity of a tissue (e.g. the $\mathrm{O}_{2}$ consumption of muscle) is matched by an increase in blood flow to that tissue. How does the blood flow to the heart and skeletal muscle increase severalfold during exercise (in association with an increase in $\mathrm{O}_{2}$ consumption), whilst the blood flow to other tissues remains unaltered or even decreases, and how does the blood flow to splanchnic tissues increase after a mixed meal, while there is relatively less change in the blood flow and $\mathrm{O}_{2}$ consumption to non-splanchnic tissues? (Brundin \& Wahren, 1991; Brundin et al. 1992). The specificity of blood flow is intriguing since leg exercise increases blood flow to the actively contracting muscles in the leg, and not to arm muscles where there may actually be a decrease in blood flow (Wade et al. 1962). Similarly an increase in neuronal activity in specific parts of the brain causes a specific increase in blood flow to the same part of the brain. For example, visual stimulation which excites the occipital cortex and somatosensory stimulation of the finger pads, which excites the perirolanderic sensorimotor cortex, have been reported to increase blood flow to the corresponding parts of the brain by $30-50 \%$ (Fox \& Raichle, 1986; Fox et al. 1988) in association with a similar increase in glucose utilization and a smaller increase in $\mathrm{O}_{2}$ consumption. The coupling between blood flow and metabolic activity of a variety of tissues requires explanation.

\section{CONTROL OF BLOOD FLOW TO MEET TISSUE DEMAND}

By virtue of its smooth muscle, the arteriole has long been recognized as being important in controlling blood flow to tissues. The role of the sympathetic nervous system and the large number of mediators that influence arteriolar tone (vascular resistance) have been the subject of several reviews. Here, only two recent developments in blood flow regulation will be considered. 


\section{Muscle blood flow and the muscle pump}

The increase in blood flow which occurs when skeletal muscle is stimulated represents one of the largest perfusion changes observed in mammalian tissues. This increase is even more remarkable when one considers that contractile tissues such as heart and skeletal muscle, both arterial and venous vessels, become occluded during the contraction phase, which typically accounts for about one-third of the time of the contractionrelaxation cycle, although this varies depending on the type of exercise and frequency of contraction. The large capacity for muscle to increase its blood flow is largely related to its high basal arteriolar tone which can be readily reduced during exercise by metabolic factors (for possible mechanisms, see pp. 219-220). The supplementary role of the muscle pump in increasing muscle perfusion has been more fully appreciated only recently.

The concept of the muscle pump, which compresses veins and causes blood to flow out of the compressed veins under the direction of the venous valves, emerged in the 1940s. Folklow et al. (1970) suggested that the muscle pump could increase muscle perfusion by increasing the arterio-venous pressure difference across muscle (i.e. by reducing the hydrostatic pressure in veins after they were compressed). Laughlin (1987) suggested that the venous pressure could be lowered even further by a mechanism independent of hydrostatic pressure, namely the elastic recoil of tissues would pull open the empty veins and create a negative intravenous pressure. The recent work of Sheriff et al. (1993) in dogs supports the concept that the muscle pump activity assists the perfusion, beginning almost immediately after the onset of muscular contraction and before metabolic vasodilation, which starts 5-20 s after muscular contraction (Marshall \& Tandon, 1984). Neither the magnitude nor the rate of rise of the vascular conductance was affected by autonomic blockage or by preventing changes in the cardiac output (although the latter reduced blood pressure). Further support for a role of the muscle pump in assisting muscle perfusion comes from direct measurement of intramuscular pressures, which were found to be $-25 \mathrm{~mm} \mathrm{Hg}$ during relaxation from static contractions in man and considerably more negative in the leg veins of walking giraffes. In the dog studies of Sheriff et al. (1993), it was estimated that the venous pressures were -30 to $-60 \mathrm{~mm} \mathrm{Hg}$.

The absence of negative pressure during pharmacological vasodilation could explain, at least in part, why maximal vasodilation induced pharmacologically produces a smaller increase in muscle blood flow than muscular contraction. However, in the studies of Sheriff et al. (1993) only a 2 -fold increase in vascular conductance above the basal values could be attributed to the muscle pump, and the initial rise in vascular conductance which depends on the muscle pump was unaffected by exercise intensity. This means that although intermittently contracting muscles can draw blood into themselves because of mechanical factors, during intense exercise metabolic vasodilation is far more important. Furthermore most tissues rely almost entirely on metabolic-neuronal vasodilation or vasoconstriction, to control their vascular conductance.

\section{Metabolic regulation of blood flow}

One of the outstanding haemodynamic aspects of metabolic regulation is the mechanism by which signals from metabolically active tissues are transmitted to the arterioles so that they can appropriately control flow to match the metabolic activity of the tissue. A wide variety of mediators are involved, and almost certainly their relative importance varies in 
different tissues, and at different times in the same tissue, e.g. the metabolic mediators that initiate vasodilation after the onset of exercise appear to be different from those that maintain it (Haddy \& Scott, 1975).

However, a variety of studies in a variety of tissues have demonstrated that lack of $\mathrm{O}_{2}$ causes vasodilation. The importance of $\mathrm{O}_{2}$ (Brown et al. 1985) as a signal has been reinforced by studies involving newly synthesized allosteric modifiers of haemoglobin, which shift the position of the haemoglobin dissociation curve to the right, so that $\mathrm{O}_{2}$ is released more readily from the haemoglobin molecule during hypoxia (Wei et al. 1993). Thus, supraperfusion of these agents on the brain of cats reduces the extent of cerebral vasodilation induced by hypotension or hypoxia. These and other studies support the concept that vasodilation is mediated by local $\mathrm{O}_{2}$-dependent mechanisms. Jackson (1987) attempted to find the location of the ' $\mathrm{O}_{2}$ sensor' on the hamster cheek pouch by comparing changes in arteriolar diameter after producing local changes in $\mathrm{O}_{2}$ partial pressure $\left(\mathrm{pO}_{2}\right)$ across the wall of arterioles, and global changes in $\mathrm{pO}_{2}$ over a wide area that included capillaries. Only global changes in $\mathrm{pO}_{2}$ altered arteriolar tone, and it was concluded that the $\mathrm{O}_{2}$ sensors were located downstream from $15 \mu \mathrm{m}$ arterioles. The data, therefore, suggest that there are sensors that detect changes of $\mathrm{O}_{2}$ available, and that these sensors transmit signals to the arteriole, which is some distance from the sensor.

Several workers have raised the possibility that the capillary can act as a 'metabolic sensor' and transmit signals to the arteriole. A new investigative approach is the micro-application of substances such as noradrenaline downstream from the supplying arteriole, which has been shown to cause constriction of the arteriole (Dietrich, 1989; Dietrich \& Tyml, 1992; Song \& Tyml, 1993). This phenomenon of remote arteriolar vasodilation-vasoconstriction could not be explained by simple diffusion from the capillary, partly because this was considered to be too slow, and partly because the effect could be blocked either by damage of the capillary or by application of blocking agents close to the capillary (Dietrich \& Tyml, 1992). For example, yohimbine blocks the effect of noradrenaline and atropine blocks the action of acetylcholine when placed close to the capillary. In contrast, pretreatment of the feeding arteriole with these blocking agents did not block the arteriolar response which implies that neither the receptors on the arteriole nor diffusion is necessary for this response. The effect could not be explained by the presence of adrenergic nerves, partly because muscle preparations lacking nerves in the region of interest, still exhibit the phenomenon, and partly because the nerve blocking agent, tetrodotoxin, did not affect the phenomenon (Dietrich \& Tyml, 1992). Communication via connective tissue elements or muscle cells, also, could not explain the phenomenon because applications of noradrenaline near fibrocytes produced no effect provided the fibrocytes were not adjacent to capillaries (Dietrich \& Tyml, 1992). These observations suggest that the capillary can act as an important sensor.

It is now recognized that the capillary senses not only noradrenaline but also a variety of other substances that affect arteriolar tone, e.g. in muscle these include acetylcholine and substances such as $\mathrm{H}^{+}, \mathrm{K}^{+}$and adenosine or adenosine analogues which are likely to accumulate during hypoxia induced by high metabolic activity (Song \& Tyml, 1993). It is likely that many weak stimuli produced by a variety of signals lead to an integrated response. For example, a single weak stimulus of noradrenaline applied to a capillary does not produce a change in arteriolar diameter, whereas the same stimulus applied to two capillaries produces a significant reduction in arteriolar diameter. Conversely, 
signals that produce opposing effects on arteriolar tone have little effect when applied simultaneously.

It is also possible that hypoxic sensing may involve a change in redox potential (NAD:NADH or GSH:GSSH), and in the electron transport (or cytochrome P450) system with generation of reactive oxygen species such as superoxide or $\mathrm{H}_{2} \mathrm{O}_{2}$. Unfortunately the electron transport and cytochrome $\mathrm{P} 450$ systems have a $K_{m}$ for $\mathrm{O}_{2}$ that is in the very hypoxic range. In contrast NADPH oxidase $(E C 1.6 .2 .5)$ which also has an electron transport system, has a $K_{m}$ for $\mathrm{O}_{2}$ tension in the physiological range. The enzyme complex is located on the plasma membrane of vascular tissue (including the chemoreceptors of the carotid body; Acker et al. 1989) where it may act as an important sensor.

Although the role of capillaries in sensing and integrating biological signals is becoming increasingly accepted, this does not explain how the signals are communicated to the arteriole. The endothelial cells are linked together by gap junctions (Simionescu et al. 1975; Huttner et al. 1993) which have been widely implicated in cell-to-cell communication, by being involved in transfer of cellular metabolites (metabolic coupling, e.g. nucleotides; Larson \& Sheridan, 1982) and transfer of ions (electronic transfer). Endothelial cells when arranged in a monolayer have a resistance that is 200-fold lower than that found in single cells (Daut et al. 1988). These cells can depolarize and hyperpolarize. Therefore, it is suggested that the capillary sensor reacts by acting as a source of hyperpolarization or depolarization that spreads electrotonically to adjacent cells towards the arteriole, and that integration of multiple signals from multiple capillaries determines the overall arteriolar response. The electrical signal from the endothelium to the adjacent cell of the arteriole seems to involve the release of vasoactive substances such as NO, endothelin and prostacyclin (Vanhoutte et al. 1991) which affect arteriolar tone by an effect on ATPase ( $E C$ 3.6.1.3)-sensitive channels (Jackson, 1993; Nakhostine \& Lamontagne, 1993).

A recent report (Bény \& Pacicca, 1994) suggests that electrical signals can also pass in the reverse direction from the muscle cell of the arteriole to the endothelial cell. Since some agents block the transmission one way and not the other, it is postulated that different communication pathways exist between muscle cells and endothelial cells. The importance of signals from the muscle to the endothelial cells is uncertain, but there is considerable scope for feedback regulation especially in states associated with high metabolic activity and high tissue blood flow (Britton et al. 1985).

These observations taken together produce a body of evidence that suggests that the capillary is not only an important metabolic sensor but that it also plays an important role in blood flow control. Capillaries are ideally situated for sensing biological signals involved in blood flow control, and they are the most widely distributed of all blood vessels. It is estimated that there are about ten billion capillaries in the human body (surface area approximately $500-700 \mathrm{~m}^{2}$ ) and that it is rare for any functional cell of the body to be more than $20-30 \mu \mathrm{m}$ away from a capillary (Guyton, 1986). This allows them to sense signals from entire regions of tissue, and particularly the regions they supply.

In summary, the control of blood flow to specific tissues appears to be determined to a large extent by metabolic events in the tissues themselves. Obviously the oxygenation of arterial blood by ventilatory control mechanisms, and maintenance of an adequate perfusion pressure and appropriate cardiac output are important in the overall integration of body metabolism. However, the metabolism of the body as well as that of individual tissues also depends not only on the supply of blood to the var ous tissues, but also on the quantities and type of substrates available in the blood. 


\section{CONTROL OF TISSUE METABOLISM BY SUBSTRATE SUPPLY}

Since many tissues have poor fuel reserves for reasons of mechanical, metabolic or functional efficiency, they depend on a constant supply of fuels from other tissues. For example, reference has already been made to the effect of glucose concentration on its uptake by the perfused hindlimb. The same applies to resting human muscle, but to demonstrate this effect in vivo it is necessary to maintain the insulin concentration constant (Yki-Jarvinen et al. 1987). When the insulin concentration is clamped to values within the physiological and the supraphysiological range $(10-1700 \mathrm{mU} / \mathrm{l})$, whilst the glucose concentration is increased from 5 to $10 \mathrm{mmol} / \mathrm{l}$ the rate of glucose uptake by the forearm (mainly muscle) also increases 2 -fold. The glucose uptake by muscle continues to increase as the glucose concentration is increased above $10 \mathrm{mmol} / 1$ (e.g. up to 22 $\mathrm{mmol} / \mathrm{l}$ in one study), but in a curvilinear manner. Obviously the supply of glucose from the liver and gut (diet) can have a substantial influence on muscle glucose uptake.

The uptake of NEFA by muscle (skeletal or cardiac muscle) also depends on the circulating NEFA concentration. Since the physiological plasma NEFA concentration varies 10 -fold $(0 \cdot 2-2 \cdot 0 \mathrm{mmol} / \mathrm{l}$; equivalent to $7-66 \mathrm{~kJ} / 1)$, which is considerably greater than the 2-fold range in physiological glucose concentrations (e.g. 3.5-7.5 mmol/l; equivalent to $10-21 \mathrm{~kJ} / \mathrm{l}$ ) there is considerable potential for NEFA to influence tissue metabolism by mass action effects. For example, the unidirectional influx of NEFA into the human heart increases 6 -fold between a plasma concentration of 0.2 and $1.6 \mathrm{mmol} / 1$ (Vyska et al. 1991). Therefore, the supply of NEFA from adipose tissue can be important in influencing both the circulating NEFA concentration and NEFA uptake in skeletal and cardiac muscle.

\section{COMPETITION BETWEEN CIRCULATING FUELS}

Since tissues frequently use more than one fuel for oxidative metabolism, it is not surprising that fuels derived from separate tissues (e.g. glucose from the liver and NEFA from adipose tissue) compete with each other for uptake and oxidation in other tissues. However, the conventional approach of expressing substrate concentrations and their rate of uptake by tissues in relation to the number of moles is somewhat misleading from the energetic point of view for at least two reasons. First, some substrates are present in both plasma and erythrocytes (e.g. glucose, ketone bodies), whilst others are almost exclusively restricted to plasma (e.g. NEFA and triacylglycerol). Second, the heat of combustion of fuels varies substantially. The heat of combustion of glucose $(2.80$ $\mathrm{MJ} / \mathrm{mol})$ is about $50 \%$ more than that of ketone bodies $(1.78 \mathrm{MJ} / \mathrm{mol}$ acetoacetic acid and 2.01 MJ/mol 3-hydroxybutyric acid) and 4-fold less than that of NEFA (10.79 $\mathrm{MJ} / \mathrm{mol}$; Elia \& Livesey, 1992). Since the availability of glucose, ketone bodies and NEFA varies substantially in different circumstances with little change in their overall combined energy content (e.g. glucose and NEFA vary in a reciprocal manner during the transition between the fed and fasted state; see pp. 226-227 and Fig. 1), competition between fuels could be an important way of influencing the fuel selection of tissues. However, it has not always been straightforward to demonstrate competition between the uptake of circulating glucose and NEFA in human tissues such as skeletal muscle, as suggested by Randle et al. (1963) following their classic work with muscle and heart preparations. Some studies in vivo and in vitro failed to demonstrate this competitive 


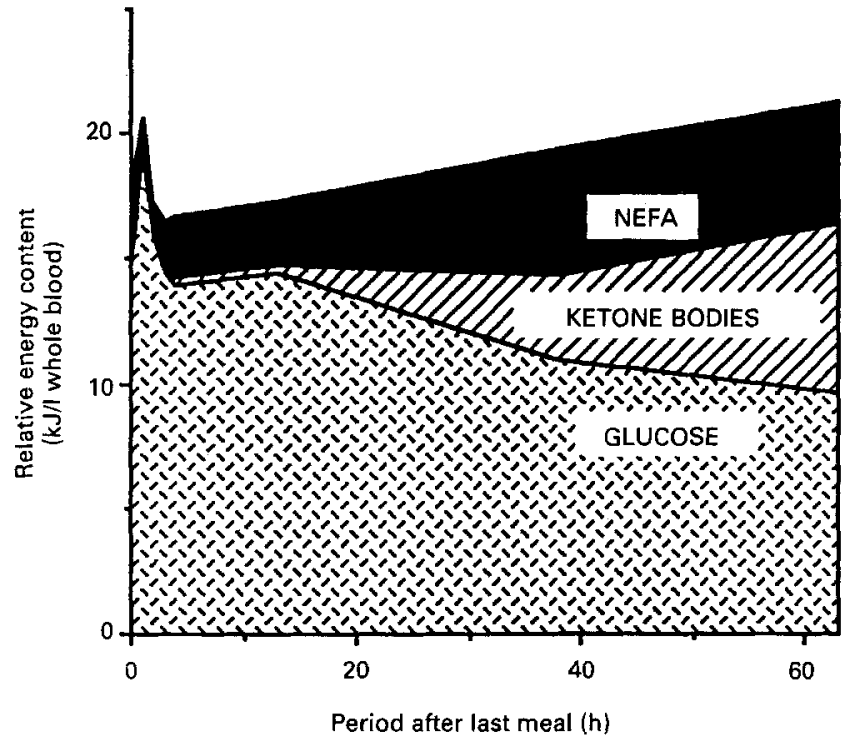

Fig. 1. This unconventional way of presenting the availability of fuels in arterial whole blood, illustrates the relative energy content of non-esterified fatty acids (NEFA), glucose and ketone bodies (sum of 3hydroxybutyric acid and acetoacetic acid) before a 12-14 h overnight fast, at time $0 \mathrm{~h}$ and during $60 \mathrm{~h}$ of starvation after ingestion of a single meal ( $3.3 \mathrm{MJ}$ consisting of $40 \%$ energy from fat, $13 \%$ energy from protein and $47 \%$ energy from carbohydrate) in healthy lean adults. Data were compiled from Elia et al. (1988a) for the early effects of the meal (0-4 h) and subsequent data from Elia et al. (1990), assuming that NEFA are restricted to the blood plasma. The energy values of glucose, NEFA, acetoacetic acid and 3-hydroxybutyric acid were taken from Elia \& Livesey (1992).

effect, whilst others have reported that NEFA may even stimulate glucose uptake. These different observations may be reconciled by considering three other factors ( $\mathrm{Li}$ et al. 1993).

First, it may be difficult to demonstrate an effect in muscles which have the metabolic machinery to predominantly oxidize only one fuel, e.g. white muscles have a particularly high preference for carbohydrate and, therefore, increasing the supply of NEFA may do little to suppress glucose utilization and oxidation in this tissue. The same concept applies to tissues such as the brain which does not utilize NEFA directly as an important energy source (although ketone bodies derived from NEFA may have an important influence). Second, it appears that the competition between circulating glucose and NEFA may be masked by the presence of glycogen and triacylglycerol (TAG; Yki-Jarvinen et al. $1991 b$ ). For example, circulating NEFA may compete with TAG, and they may even be converted to TAG in muscle. Third, it can be difficult to demonstrate an effect of NEFA on glucose uptake in situations where the uptake of NEFA relative to glucose is already high (e.g. during fasting). Under these conditions a large increment in the availability of NEFA can only suppress glucose uptake and oxidation by a small amount, and the esterification that may result from excess uptake of NEFA may actually increase the uptake of glucose, which is necessary for the formation of the glycerol moiety of TAG.

In an attempt to demonstrate an effect of circulating NEFA on glucose uptake by muscle some workers have produced a moderate increment in NEFA (approximately 2 
$\mathrm{mm}$ ) by administering heparin in association with a TAG emulsion, in a situation where glucose uptake is already high and NEFA uptake low (hyperinsulinaemic-euglycaemic clamping; Nuutila et al. 1992). Under such circumstances elevation of the circulating NEFA concentration decreased glucose uptake by up to $30 \%$, as measured by arterio-venous catheterization techniques (forearm muscle; Yki-Jarvinen et al. 1991a) or position emission tomography (PET; arm and leg muscles; Nuutila et al. 1992). PET also demonstrated a substantial and simultaneous decrease in the uptake of glucose by the heart.

In some situations two or more tissues in series may be involved in the supply of a nutrient to another tissue. For example, during fasting, when glycogen reserves are depleted and blood glucose concentration is reduced, the brain may derive as much as two-thirds of its energy from ketone bodies (Owen et al. 1967). Although starvation may induce changes in transport of ketone bodies from the blood to the brain, it is still generally believed that the most important determinant of ketone-body uptake is their circulating concentration (Robinson \& Williamson, 1980). The liver again acts as the source of fuel (ketone bodies), but for ketogenesis to occur actively there must be a constant supply of NEFA. Therefore, the brain depends on the liver for the supply of ketone bodies and the liver depends on adipose tissue for a supply of NEFA.

\section{SUBSTRATE SUPPLY: THE DIET OR THE TISSUE?}

The importance of the diet in providing fuels such as carbohydrate for almost immediate tissue utilization is discussed later (pp. 226-227). However, the inter-organ flux of some substrates in both the fed and fasted state is far greater than the quantities provided in the diet. It follows that tissues that produce these substrates are more likely to control the supply to other tissues than dietary intake. For example, the inter-organ flux of glutamine in man is at least $\mathbf{2 4} \mathrm{g} / \mathrm{d}$, which is 5-fold greater than the dietary intake (Elia, 1992a,b 1993). In injury the inter-organ flux of glutamine increases considerably and the dietary intake decreases considerably, so that the difference between glutamine intake and net inter-organ flux becomes very large ( $>10$-fold).

Since tissues that utilize glutamine, e.g. the small intestine and lymphocytes, have little capacity to synthesize glutamine, they depend on a constant supply of glutamine from tissues such as muscle, lung and adipose tissue which produce it. The lactating mammary gland of ruminants also has little capacity to synthesize glutamine and, therefore, it too depends on a supply of glutamine from the circulation. Glutamine and its counterpart glutamic acid, which are the most abundant amino acids in bovine milk, are actively taken up by the mammary gland. By considering the rate of glutamic acid production in the mammary gland (glutamine can be converted to glutamic acid by the action of glutaminase $(E C$ 3.5.1.2)) and the fractional uptake of glutamine, which is essentially $100 \%$ of the arterial supply $(>185 \mu \mathrm{mol} / 1$, which is the intercept value where there is no net exchange), Meijer et al. (1993) suggested that glutamine could be the rate-limiting amino acid for milk production in high-yielding dairy cows. Whether this is true or not is uncertain, but the observations emphasize the potential importance of glutamine supply from muscle and other tissues that synthesize it and release it into the circulation. The observations also raise the possibility that glutamine, a 'non-essential' amino acid, may become conditionally essential in some circumstances, a concept supported by a number of other workers (e.g. Lacey \& Wilmore, 1990). 
An inadequate supply of one substrate from one tissue to another can explain the dramatic effects of a single arginine-free meal to cats, which can result in their death within a few hours (MacDonald \& Rogers, 1984; Anon, 1985; Rogers \& Phang, 1985). Arginine is generally considered to be a non-essential amino acid in man, but carnivores appear to have lost the ability to synthesize it. Clues to the mechanism of the toxicity produced by an arginine-free meal come from four sources: the rise in blood $\mathrm{NH}_{3}$ concentration; the reduced hepatic concentrations of urea-cycle intermediates (arginine, citrulline and ornithine); the reduced excretion of urea which is replaced by orotic acid; prevention or correction of the toxicity by administration of any of three urea-cycle intermediates (arginine, citrulline, ornithine). In the fasting state arginine is made available to the liver from the breakdown of lean tissues, but in the fed state it is diverted to peripheral pools where protein synthesis occurs. It, therefore, is not available to the circulating concentration in sufficient quantities and becomes rate-limiting to the production of urea which utilizes $\mathrm{NH}_{3}$. In the presence of this metabolic block, $\mathrm{NH}_{3}$ is diverted to orotic acid which is excreted in urine. In many mammals the amino acid ornithine, which is one of the urea-cycle intermediates, is supplied to the liver from the gut where it is synthesized from glutamate. Ornithine can prevent or restore the metabolic block (ureagenesis) since it is a urea-cycle intermediate that is interconvertible with arginine and other urea-cycle intermediates. However, carnivores such as the cat have lost the ability to synthesize ornithine and, therefore, they cannot restore the defect produced by arginine-free meals.

There are human parallels to this situation. In the early days of parenteral nutrition a number of amino acids were omitted from commercial amino acid mixtures in the belief that they could be adequately synthesized by human tissues. Whilst this is generally true of adults, some newborn infants, particularly premature infants who have immature enzyme systems, cannot synthesize sufficient ornithine and, therefore, they suffer a metabolic disturbance analogous to that observed in carnivores (Winters et al. 1983). The administration of arginine with the intravenous feeds reverses the metabolic abnormalities. These observations not only provide a dramatic demonstration of the importance of substrate supply from one tissue to another, they also suggest that in some situations, the rate-limiting step for ureagenesis can differ between species and at different stages of development in the human species.

\section{EXTRAVASCULAR SUPPLY OF NUTRIENTS}

Much of what has been discussed about substrate supply has involved the circulation. For some tissues an extravascular supply of nutrients can be important. The gut is unique in deriving pools not only from the blood but also from the lumen of the gut. One estimate is that the small bowel derives $45 \%$ of its oxidative substrate from the lumen of the gut and the colon as much as $70 \%$ from the lumen (Roediger, 1986). The mucosa of the large intestine can derive a substantial amount of energy from one of the short-chain fatty acids (butyrate) which is an endproduct of fermentation in the large bowel. This fermentation utilizes carbohydrate (fibre, resistant starch and oligosaccharides) that escapes digestion in the small intestine. If fermentation is limited by the ingestion of a fibre-free diet or by a large reduction in food intake, butyrate production is reduced and, therefore, it is unable to exert its effects on epithelial cell proliferation and differentiation, in increasing local blood flow, and in competing with other energy substrates, which now become the dominant fuels for colonocytes. 
The early pre-implantation embryo derives its energy not only from its own stores of substrates, which were initially present in the ovum, but also from the mucosal secretions of the fallopian tube and uterus. These secretions also facilitate cell division and gaseous exchange. Studies of fuel selection during early embryonic development in both animals (Leese \& Barton, 1984; Gardner \& Leese, 1986) and man (Hardy et al. 1989; before the blastocyst stage) suggest that pyruvate is preferred and utilized to a considerably greater extent than glucose. Indeed, glucose appears to inhibit cell division at this stage of development, and this is of considerable interest to those involved in producing appropriate culture media for in vitro fertilization especially since recent reports suggest that $50 \%$ of fertilized eggs suffer from early maturation arrest at the blastocyst stage. Pregnancy rates following in vitro fertilization and transfer were still only $17 \%$ in 1990 . One possible explanation is that the culture medium is inadequate or suboptimal for supporting early embryonic development. Perhaps a medium containing pyruvate and lactate, and glucose at a concentration of approximately $1 \mathrm{mmol} / \mathrm{l}$, which is close to the physiological concentration in the secretions of the fallopian tube, is more appropriate.

\section{TISSUE-DIRECTED NUTRIENT FLUX: CHANGES IN THE AFFINITY OF TISSUES FOR SUBSTRATES}

The specific fuel requirements of the early embryo have little quantitative impact on the metabolism of whole body, but the specific requirements of other tissues, such as injured tissues, may have major effects on whole metabolism.

The burn wound derives a large proportion of its energy from glycolysis. Therefore, the uptake of glucose and release of lactate by a leg with a large burn can be 5-10-fold greater than that of one with a small burn. In a man with a $50 \%$ leg burn (Wilmore \& Aulick, 1978) it is estimated that the wound utilizes 200-225 g glucose and this doubles the normal glucose utilization of approximately $220 \mathrm{~g} / \mathrm{d}$ after an overnight fast $(120 \mathrm{~g} / \mathrm{d}$ by the brain and $100 \mathrm{~g} / \mathrm{d}$ by other tissues). However, since the percentage of total glucose oxidized in the whole body is reduced in burns (approximately $33 v .65 \%$ under normal circumstances) about $250 \mathrm{~g}$ glucose/d are recycled, compared with about $75 \mathrm{~g} / \mathrm{d}$ under normal circumstances (overnight fast).

The release of lactate and other 3-carbon glycolytic fragments by the wound acts as a source of gluconeogenic substrate for the liver. In injury the set-point for gluconeogenesis is altered and this exemplifies another way in which metabolism between tissues can be modulated. In the perfused liver the uptake of gluconeogenic substrates such as lactate and alanine and glycerol is dependent on the concentration of these substrates in the medium perfusing it. In man, too, the uptake of gluconeogenic substrates such as alanine and glycerol depend on their circulating concentration. In injury the set-point for gluconeogenesis in the liver is altered so that gluconeogenesis is enhanced. For example, the fractional splanchnic uptake of amino acids such as alanine is increased after injury despite an increase in splanchnic blood flow. In addition, hyperglycaemia and glucose administration fail to suppress gluconeogenesis, as occurs under normal circumstances. Thus, the circulating concentration of substrates such as alanine may remain unaltered or even decrease despite a major increase in the release of this amino acid by peripheral tissues. The pattern of amino acids released by peripheral tissues mirrors the pattern of amino acid uptake by the splanchnic tissues both under normal circumstances and after injury. Although traditionally this has been explained by the influence of substrate 
supply from peripheral tissues on hepatic metabolism, it is conceivable that the reverse may also apply. The increased hepatic demand for amino acids for gluconeogenesis, and for the synthesis of acute-phase proteins and other hepatic proteins, which increase the mass of the liver even in the face of a negative $\mathrm{N}$ balance, could influence the release of amino acids and the catabolism of peripheral tissues. Certainly altered set-points for gluconeogenesis can affect the circulating concentration of amino acids, which have been demonstrated to influence various metabolic processes including protein synthesis, independently of insulin (Watt et al. 1992).

Changes in the set-point for utilization of substrates can also be altered in physiological states such as lactation, where TAG is directed to the mammary gland by virtue of a major increase in the activity of lipoprotein lipase $(E C 3.1 .1 .34)$ in this tissue and a decrease in its activity in adipose tissue. Tissue-specific changes in lipoprotein lipase also occur during starvation, where there is an increase in its activity in muscle and a decrease in its activity in adipose tissue. These changes direct TAG away from adipose tissue, and favour utilization by other tissues. In contrast, after mixed meal ingestion there is a late activation of lipoprotein lipase, which occurs at the time that circulating TAG concentrations are maximal (Frayn et al. 1994).

\section{HORMONAL CONTROL}

Several of the previously mentioned changes, as well as the changes in blood flow and metabolism of tissue are under control or modification by circulating regulators in the form of hormones and cytokines. A detailed discussion of hormonal regulation of metabolism is beyond the scope of the present review. Here it is probably more relevant to describe the integrated responses that occur during two of the most important physiological events in daily life (feeding and exercise) and the role of catecholamines and the autonomic nervous system which mobilize fuels during exercise and insulin, which helps store fuels after meal ingestion.

\section{Meal ingestion}

Surprisingly, information about the quantitative effects of mixed meal ingestion on individual tissue metabolism in man has been obtained only recently. Studies of the metabolite exchanges across human muscle (Elia et al. 1988a,b, 1989), adipose tissue (Frayn et al. 1994) and splanchnic tissues (Brundin \& Wahren, 1991; Brundin et al. 1992) provide the following picture in which insulin mediates or facilitates two of the most important postprandial events; a reduction in the release of endogenous fuels, such as glucose, by the liver (inhibition of glycogenolysis and gluconeogenesis), and NEFA by adipose tissue (inhibition of hormone-sensitive lipase (EC 3.1.1.3)), and an increase in the utilization of exogenous fuels for storage purposes. It stimulates glucose transport in muscle and glycogen synthesis in both muscle and liver. In human muscle in vivo it appears that insulin affects the rate-limiting step for glucose utilization, i.e. transport or possibly an intracellular metabolic event (Yki-Jarvinen et al. 1987). In adipose tissue insulin stimulates TAG uptake by activating lipoprotein lipase (also by low NEFA concentrations; Petersen et al. 1990), which responds slowly to match the slow increase in circulating TAG concentrations (due to delays in absorption and processing of fat in the gut and liver). 
The combination of hyperglycaemia (absorption of glucose) and low NEFA concentrations (insulin-mediated reduction in NEFA release by adipose tissue) increases the proportion of energy derived from carbohydrate oxidation and reduces that derived from fat oxidation in the whole body and several of its tissues. Thus, the uptake of NEFA by muscle decreases and that of glucose increases (Elia et al. 1988a). The uptake of glucose by muscle, under the stimulatory effect of insulin, is more than sufficient to cater for the total energy requirement of resting muscle. The excess uptake of glucose- $\mathrm{C}$ is not accompanied by an increase in the release of $\mathrm{C}_{3}$ glycolytic fragments, which means that the excess glucose is stored in muscle, probably as glycogen (Elia et al. 1988a). It is estimated that during the first $4 \mathrm{~h}$ after a meal containing $3.3 \mathrm{MJ}$, more than half the dietary carbohydrate, which accounted for $47 \%$ of dietary energy intake, was taken up by muscle and that about half this was deposited as glycogen (Elia et al. 1988a). NMR suggests that $26-35 \%$ of the absorbed carbohydrate is stored in muscle after a large carbohydrate-rich meal (Taylor et al. 1993). Some is converted to glycogen in nonmuscular tissues especially the liver (again under the stimulatory effect of insulin), a small amount of it is used to expand the free glucose pool, and the remainder is oxidized. The hyperglycaemia, also, will tend to reduce net hepatic glucose production by primitive mechanisms (Nordie, 1985). Since, under normal circumstances, the circulating glucose pool is only about $25 \mathrm{mmol}(4.5 \mathrm{~g}$; equivalent to about $71 \mathrm{~kJ})$ and the total pool 3 -fold greater than this, and since endogenous glucose production is suppressed, the tissues of the body will quickly begin to use exogenous carbohydrate as a major energy source.

Following meal ingestion the amino acid balance across muscle reverts from being negative to positive (Elia et al. 1988b; Elia, 1992b; again mediated by insulin, and there is an increase in the concentration of many amino acids) and the pattern of amino acids taken up and released by muscle is distinct. With so many processes taking place in a variety of tissues, it is not surprising that energy expenditure increases in a variety of tissues (Brundin \& Wahren, 1991; Brundin et al. 1992). However, almost half the increase occurs in the splanchnic bed. This is accompained by a parallel increase in blood flow. The percentage increase in energy expenditure and in blood flow to non-splanchnic tissues is relatively lower. Interscapular brown fat does not appear to be an important site of dietary-induced thermogenesis in man (Brundin \& Wahren, 1991).

\section{Exercise}

The most important control processes during exercise involve the large increase in the flow of blood, $\mathrm{O}_{2}$ and nutrients to muscle, and the mobilization of fuels for oxidative purposes (if there is storage of nutrients after meal ingestion). The metabolic control of exercise hyperaemia has been discussed, as has the supplementary role of the muscle pump. Catecholamines and the autonomic nervous system also produce vasodilation in the vasculature of muscle and, therefore, contribute to the increase in muscle blood flow. The autonomic nervous system and the increase in circulating concentration of catecholamines, especially adrenaline, have a central role in mediating increased activity in a variety of tissues, such as the lung (increased rate and depth of respiration), heart (increased cardiac output), liver (increased glucose output, e.g. glycogenolysis), adipose tissue (increased release of NEFA, an effect on hormone-sensitive lipase, which can be produced by nerve stimulation in adipose tissue preparations (Correl, 1963) as well as 
circulating catecholamines) and muscle (increased glycogenolysis, which is also mediated by changes in metabolite concentrations within muscle).

The quantitative aspects of endogenous fat and carbohydrate metabolism in relation to exercise intensity have recently been re-evaluated. Catecholamines clearly play an important role in fuel mobilization (Romjin et al. 1993). Other hormones are also involved in fuel mobilization. For example, the circulating glucagon concentration which increases after exercise, causes glycogenolysis in the liver. The blood glucose concentration remains relatively unaffected in the early stages of exercise and, therefore, is unlikely to be an important regulator of hepatic glucose output during this period, although it can be implicated during more prolonged exercise when its circulating concentration decreases.

During exercise blood flow is increased to the lungs (for gaseous exchange), heart (for increased cardiac work), and adipose tissue (for supply of NEFA). Catecholamines are again causally involved in many of these processes.

There must also be important feedback mechanisms to ensure circulatory and metabolic homeostasis. The role of baroreceptors (Potts et al. 1993), which send signals to the vasomotor centre, joint reflexes, which increase respiration, and chemoreceptors, which sense oxygen availability are well known. The enormous blood flow to the chemoreceptors ( 2 litres/100 g per min in the cat; Daly et al. 1954; Eyzaguirre et al. 1983) emphasizes the importance of ensuring an adequate blood flow to this important $\mathrm{O}_{2}$ sensor.

\section{CONCLUSION}

Essentially all tissues receive and send signals to other tissues. Some of these signals have generalized effects, e.g. thyroid hormone, whilst others are primarily targeted to specific tissues, e.g. erythropoietin which is produced by the kidney stimulates erythropoiesis in the bone marrow. Vitamin D probably has multiple effects in a variety of tissues and its metabolic pathway is particularly interesting since it spans across a series of tissues. The skin forms cholecalciferol under the influence of u.v. light, the liver converts the cholecalciferol to 25-hydroxycholecalciferol, the kidney hydroxylates the 25hydroxycholecalciferol further to 1,25-dihydroxycholecalciferol, and finally the gut and bone respond to cholecalciferol. The reason for this sequence of metabolic events in different tissues is not clearly understood. The rate-limiting step in cholecalciferol metabolism may arise in different tissues, such as the skin when there is low exposure to sunlight, or the kidney in patients with renal disease. In those in whom exposure to sunlight is minimal the rate-limiting step can also be an inadequate dietary intake.

The presence of 1,25-dihydroxycholecalciferol receptors in most tissues of the body, including the reproductive tract and glands such as the pancreas, requires a new theoretical approach to explain the functions of cholecalciferol which probably extend far beyond those originally envisaged in bone (DeLuca, 1993). For example, vitamin D deficiency in animals impairs reproduction and insulin secretion. The discovery in 1989 that vitamin D may have an important role in cell differentiation has been associated with the development of new synthetic analogues of vitamin $\mathrm{D}$ (calcipitriol), which are marketed for the treatment of psoriasis (associated with proliferation and a differentiation of keratinocytes; Holick et al. 1989), and exploration of the possible role of vitamin $\mathrm{D}$ and its analogues in cancer therapy (Eisman et al. 1989). 
Haemodynamic, neuronal, hormonal and circulating substrate concentrations, as well as gaseous exchange are all intimately linked. Although the present paper has provided insight into some of the inter-organ control mechanisms that allow the body to function effectively in a coordinated manner, it has to be admitted that many of the details of the integrative processes, and function of some bioactive substances are still lacking.

\section{REFERENCES}

Acker, H., Dufau, E., Haber, J. \& Sylvester, D. (1989). Indications to an NADPH oxidase as a possible $\mathrm{pO}_{2}$ sensor in the rat carotid body. FEBS Letters 256, 75-78.

Andersen, P. \& Saltin, B. (1986). Maximal perfusion of skeletal muscle in man. Journal of Physiology 62, $1285-1298$.

Anon (1985). Intestinal ornithine synthesis from glutamic acid. Nutrition Reviews 43, 119-121.

Baron, A. D. \& Brechtel, G. (1993). Insulin differentially regulates systemic and skeletal muscle vascular resistance. American Journal of Physiology 265, E61-E67.

Baron, A. D., Steinberg, H., Brechtel, G. \& Johnson, A. (1994). Skeletal muscle blood flow independently modulates insulin mediated glucose uptake. American Journal of Physiology 266, E248-E253.

Bény, J.-L. \& Pacicca, C. (1994). Bidirectional electrical communication between smooth muscle and endothelial cells in the pig coronary artery. American Journal of Physiology 266, H1465-H1492.

Britton, S. L., Metting, P. J., Ronau, T. F., Strader, J. R. \& Weldy, D. L. (1985). Autoregulation and hind limb blood flow in conscious dogs. Journal of Physiology 368, 409-422.

Brown, M. M., Wade, J. P. H. \& Marshall, J. (1985). Fundamental importance of arterial oxygen content in the regulation of cerebral blood flow in man. Brain 108, 81-93.

Brundin, T., Thorne, A. \& Wahren, J. (1992). Heat leakage across the abdominal wall and meal induced thermogenesis in normal weight and obese subjects. Metabolism 41, 49-55.

Brundin, T. \& Wahren, J. (1991). Influence of a mixed meal on splanchnic and interscapular energy expenditure in humans. American Journal of Physiology 260, E232-E237.

Bulow, J. \& Madsen, J. (1976). Adipose tissue blood flow during prolonged heavy exercise. Pflügers Archives 363, 231-236.

Bulow, J. \& Madsen, J. (1981). Influence of blood flow on fatty acid mobilization from lipolytically active adipose tissue. Pflügers Archives 390, 169-174.

Correl, J. W. (1987). Adipose tissue: ability to respond to nerve stimulation in vitro. Science 140, 387-388.

Daly, M. de B., Lambertsen, G. J. \& Schweitzer, A. (1954). Observations on the volume of blood flow and oxygen utilization of the carotid body in the cat. Journal of Physiology 125, 67-89.

Daut, J., Mehrke, G., Nees, S. \& Newman, W. H. (1988). Passive electrical properties and electrogenic sodium transport in cultured guinea pig coronary endothelial cells. Journal of Physiology 102, 237-254.

DeLuca, H. D. (1993). Vitamin D: 1993. Nutrition Today 28, 6-11.

Dietrich, H. A. (1989). Effect of locally applied epinephrine and norepinephrine on blood flow diameter in capillaries of rat mesentery. Microvascular Research 38, 125-135.

Dietrich, H. A. \& Tyml, K. (1992). Capillary as a communicating medium. Microvascular Research 42, 87-99.

Donald, K. W., Wormald, P. N., Taylor, S. H. \& Bishop, J. M. (1957). Changes in the oxygen content of femoral venous blood and leg blood flow during leg exercise in relation to cardiac output response. Clinical Science 16, 567-591.

Eisman, J. A., Koga, M., Sutherland, R. L., Barkla, D. H. \& Tutton, P. J. M. (1989). 1,25-Dihydroxyvitamin $\mathrm{D}$, and the regulation of human cancer cell replication. Proceedings of the Society for Experimental Biology and Medicine 191, 221-226.

Elia, M. (1992a). The inter-organ flux of substrates in fed and fasted man as measured by arterio-venous balance studies. Nutrition Research Reviews 4, 3-31.

Elia, M. (1992b). Glutamine in parenteral nutrition. International Journal of Food Sciences and Nutrition 43, $47-59$.

Elia, M. (1993). Glutamine metabolism in human adipose tissue in vivo. Clinical Nutrition 12, 51-53.

Elia, M., Folmer, P., Schlatmann, A., Goren, A. \& Austin, S. (1988a). Carbohydrate, fat and protein metabolism in muscle and in the whole body of man after mixed meal ingestion. Metabolism 37, 542-551.

Elia, M., Folmer, P., Schlatmann, A., Goren, A. \& Austin, S. (1988b). Amino acid metabolism in muscle and in the whole body of man before and after ingestion of a single meal. American Journal of Clinical Nutrition 49, 1203-1210. 
Elia, M. \& Livesey, G. (1992). Energy expenditure and fuel selection in biological systems: the theory and practice of calculations based on indirect calorimetry and tracer methods. International Review of Nutrition and Dietetics 70, 68-131.

Elia, M., Wood, S., Khan, K. \& Pullicino, E. (1990). Ketone body metabolism in lean male adults during short-term starvation with particular reference to forearm muscle metabolism. Clinical Science 78, 579-584.

Eyzaguirre, C., Fitzgerald, R., Lahiri, S. \& Zapata, P. (1983). Arterial chemoreceptors. In Handbook of Physiology, Section 2, vol. 3, The Cardiovascular System, pp. 557-621 [J. T. Shepherd, F. M. Abboud and S. R. Geiger, editors]. Bethesda, Maryland: American Physiological Society.

Folklow, B., Gaskell, P. \& Waaler, B. A. (1970). Blood flow through limb muscles during heavy rhythmic exercise. Acta Physiologica Scandinavica 80, 61-72.

Fox, P. T. \& Raichle, M. E. (1986). Focal uncoupling of cerebral blood flow and oxidative metabolism during somato-sensory stimulation in human subjects. Proceedings of the National Academy of Sciences, USA 83, $1140-1144$.

Fox, P. T., Raichle, M. E., Mintun, M. A. \& Dence, C. (1988). Non-oxidative glucose consumption during focal physiologic activity. Science 41, 462-464.

Frayn, K. N., Shadid, S., Hamlani, R., Humphreys, S. M., Clark, M. L., Fielding, B. A., Boland, O. \& Coppack, S. W. (1994). Regulation of fatty acid movement in human adipose tissue in the post-absorptiveto-post-prandial transition. American Journal of Physiology 266, E308-E317.

Gardner, D. K. \& Leese, H. J. (1986). Non-invasive measurement of nutrient uptake by single cultured pre-implantation mouse embyros. Human Reproduction 1, 25-27.

Guyton, A. (1986). Capillary dynamics and exchange of fluid between the blood and intestitial fluid. Textbook of Medical Physiology, pp. 348-360. London: W. B. Saunders Co.

Haddy, F. J. \& Scott, J. B. (1975). Metabolic factors in peripheral circulating regulation. Federation Proceedings 34, 2006-2011.

Hardy, K., Handyside, A. H. \& Winston, R. M. L. (1989). The human blastocyst: cell number, death and allocation during late pre-implantation development in vitro. Development 107, 597-604.

Hodgetts, V., Coppack, S. W., Frayn, K. N. \& Hockaday, T. D. R. (1991). Factors controlling fat mobilization from human subcutaneous adipose tissue during exercise. Journal of Applied Physiology 71, 445-451.

Holick, M. F. (1989). 1,25-Dihydroxyvitamin D and the skin: a unique application for the treatment of psoriasis. Proceedings of the Society for Experimental Biology and Medicine 191, 246.

Huttner, I., Boutet, M. \& More, R. (1973). Gap junctions in arterial endothelium. Journal of Cell Biology 57, 247-252.

Jackson, W. F. (1987). Arteriolar oxygen reactivity, where is the sensor? American Journal of Physiology 253, H1120-H1126.

Jackson, W. F. (1993). Arteriolar tone is determined by activity of ATP-sensitive potassium channels. American Journal of Physiology 265, H1797-H1803.

Kovach, A. G. B., Rosell, S., Sandor, P., Koltay, E., Kovach, E. \& Tomka, N. (1970). Blood flow, oxygen consumption, and free fatty acid release in subcutaneous adipose tissue during hemorrhagic shock in control and phenoxybenzamine-treated dogs. Circulation Research 26, 733-741.

Kurpad, A., Khan, K., Calder, A. G., Coppack, S., Frayn, K., Macdonald, I. \& Elia, M. (1994). Effect of noradrenaline on glycerol turnover and lipolysis in the whole body and subcutaneous abdominal adipose tissue in vivo. Clinical Science 86, 177-184.

Laakso, M., Edelman, S. V., Brechtel, G. \& Baron, A. D. (1990). Decreased effect of insulin to stimulate skeletal muscle blood flow in obese man: a novel mechanism for insulin resistance. Journal of Clinical Investigation 85, 1844-1852.

Lacey, J. M. \& Wilmore, D. W. (1990). Is glutamine a conditionally essential amino acid? Nutrition Reviews 48, $297-304$.

Larson, D. M. \& Sheridan, J. D. (1982). Intercellular junctions and transfer of small molecules in primary vascular endothelial cultures. Journal of Cell Biology 92, 183-191.

Laughlin, M. H. (1987). Skeletal muscle blood flow capacity. Role of muscle pump in exercise hyperemia. American Journal of Physiology 253, H993-H1004.

Leese, H. J. \& Barton, A. M. (1984). Pyruvate and glucose uptake by mouse ova and pre-implantation embryos. Journal of Reproduction and Fertility 72, 9-13.

Li, J., Stillman, S., Clore, J. N. \& Blackard, W. G. (1993). Skeletal muscle lipids and glycogen mask substrate competition (Randle cycle). Metabolism 42, 451-456.

MacDonald, M. L. \& Rogers, G. R. (1984). Nutrition of the domestic cat, a mammalian carnivore. Annual Review of Nutrition 4, 521-562. 
Madsen, J., Bulow, J. \& Nielsen, N. E. (1986). Inhibition of fatty acid mobilization by arterial free fatty acid concentration. Acta Physiologica Scandinavica 127, 166.

Marshall, J. M. \& Tandon, H. C. (1984). Direct observations of muscle arterioles and venules following contraction of skeletal muscle fibres in the rat. Journal of Physiology 350, 447-459.

Meijer, G. A. L., van der Meulen, J. \& Vuuren, A. M. (1993). Glutamine is a potentially limiting amino acid for milk production in dairy cows, a hypothesis. Metabolism 42, 358-364.

Nakhostine, N. \& Lamontagne, D. (1993). Adenosine contributes to hypoxia induced vasodilation through ATP-sensitive $\mathrm{K}^{+}$channel activation. American Journal of Physiology 265, H1289-H1293.

Nordie, R. C. (1985). Fine tuning of blood glucose concentrations. Trends in Biochemical Science 10, 70-75.

Nuutila, P., Koivista, V. A., Knuuti, J., Ruotsalainen, V., Teras, M., Haaparanta, M., Bergman, J., Solin, O., Voipio-Pulkki, L.-M., Wegelius, V. \& Yki-Jarvinen, H. (1992). Glucose-free fatty acid cycle operates in human heart and skeletal muscle in vivo. Journal of Clinical Investigation 28, 897-916.

Owen, O. E., Morgan, A. P. \& Kemp, H. G. (1967). Brain metabolism during fasting. Journal of Clinical Investigation 46, 1589-1595.

Peterson, J., Bihain, B. E., Bengtsson-Olivecrona, G., Deckelbaum, R. J, Carpentier, Y. A. \& Olivecrona, J. (1990). Fatty acid control of lipoprotein lipase: a link between energy metabolism and lipid transport. Proceedings of the National Academy of Sciences, USA 87, 909-913.

Potts, J. T., Shi, X. R. \& Raven, P. B. (1993). Carotid baroreflex responsiveness during dynamic exercise in humans. American Journal of Physiology 265, H1928-H1938.

Randle, P. J., Garland, P. B., Hales, C. N. \& Newsholme, E. A. (1963). The glucose fatty acid cycle: its role in insulin sensitivity and the metabolic disturbances in diabetes mellitus. Lancet $\mathbf{1}, 785-789$.

Robinson, A. M. \& Williamson, D. H. (1980). Physiological roles of ketone bodies as substrates and signals in mammalian tissues. Physiological Reviews 60, 143-186.

Roediger, W. E. W. (1986). Metabolic basis of starvation diarrhoea: implications for treatment. Lancet i, 1082-1085.

Rofe, A. M. \& Williamson, D. H. (1983). Mechanism for the 'anti-lipolytic' action of vasopressin in the starved rat. Biochemical Journal 212, 899-902.

Rogers, Q. R. \& Phang, J. M. (1985). Deficiency of pyrroline-5-carboxylate synthase in the intestinal mucosa of the cat. Journal of Nutrition 115, 146-150.

Romjin, J. A., Coyle, L., Sidossis, L. S., Gastaldelli, A., Horowitz, J. F., Endert, E. \& Wolfe, R. R. (1993). Regulation of endogenous fat and carbohydrate metabolism in relation to exercise intensity and duration. American Journal of Physiology 265, E380-E391.

Rowell, L. B., Saltin, B., Kiens, B. \& Christensen, N. J. (1986). Is peak blood flow in humans even higher during exercise and hypoxemia. American Journal of Physiology 251, H1038-H1044.

Schultz, T. A., Lewis, S. B., Westbie, D. K., Gerich, J. E., Rushakoff, R. J. \& Wallin, J. D. (1977). Glucose delivery - a clarification of its role in regulating glucose uptake in rat skeletal muscle. Life Sciences $\mathbf{2 0}$, 733-736.

Sheriff, D. D., Rowell, L. B. \& Scher, A. M. (1993). Is rapid rise in vascular conductance at onset of dynamic exercise due to muscle pump? American Journal of Physiology 265, H1227-H1234.

Simionescu, M., Simionescu, N. \& Palade, G. E. (1975). Segmental differentiations of cell junctions in the vascular endothelium. Journal of Cell Biology 67, 863-885.

Song, H. \& Tyml, K. (1993). Evidence for sensing and integration of biological signals by the capillary network. American Journal of Physiology 265, H1235-H1242.

Taylor, R., Price, T. B., Katz, L. D., Shulman, R. G. \& Schulman, G. I. (1993). Direct measurement of change in muscle glycogen concentration after a mixed meal in normal subjects. American Journal of Physiology 265, E224-E227.

Vanhoulte, P. M. (1991). Review in depth: endothelial cell mediators of vascular reactivity, Coronary Artery Disease 2, 291-338.

Vyska, K., Meyer, W., Stermmel, W., Notohamiprodjo, G., Minami, K., Machulla, H.-J., Gleichmann, U., Meyer, H. \& Körfer, R. (1991). Fatty acid uptake in normal human myocardium. Circulation Research 69, $857-870$.

Wade, O. L., Bishop, J. M. \& Donald, K. W. (1962). Cardiac Output and Regional Blood Flow, pp. 95-107. Oxford: Blackwell Scientific Publications.

Watt, P. W., Corbett, M. E. \& Rennie, M. J. (1992). Stimulation of protein synthesis in pig skeletal muscle by infusion of amino acids during constant insulin availability. American Journal of Physiology 263, E452-E460. 
Wei, E. P., Randad, R. S., Levasseur, J. E., Abraham, D. J. \& Kontos, H. A. (1993). Effect of local change in $\mathrm{O}_{2}$ saturation of hemoglobin on cerebral vasodilation from hypoxia and hypotension. American Journal of Physiology 265, H1439-H1443.

Wilkinson, G. R. \& Shand, D. G. (1975). A physiological approach to hepatic drug clearance. Clinical Pharmacology and Therapeutics 18, 377-390.

Wilmore, D. W. \& Aulick, L. H. (1978). Metabolic changes in burned patients. Surgical Clinics of North America 58, 1173-1187.

Winters, R. W., Heird, W. C. \& Dell, R. B. (1983). Parenteral amino acid nutrition in infants. In Amino Acid Metabolism and Medical Applications, pp. 327-336 [G. L. Blackburn, J. P. Grant and V. R. Young, editors]. Boston, Bristol, London: John Wright PSG Inc.

Yki-Jarvinen, H., Puhakainen, I. \& Koivisto, V. A. (1991a). Effect of free fatty acids on glucose uptake and non-oxidative glycolysis across human forearm tissues in the basal state and during insulin stimulation. Journal of Clinical Endocrinology and Metabolism 72, 1268-1277.

Yki-Jarvinen, H., Puhakainen, I., Saloranta, C., Groop, L. \& Taskinen, M.-R. (1991b). Demonstration of a novel feedback mechanism between FFA oxidative from intracellular intravascular sources. American Journal of Physiology 260, E680-E684.

Yki-Jarvinen, H., Young, A. A., Lamkin, C. \& Foley, J. E. (1987). Kinetics of glucose disposal in whole body and across the forearm in man. Journal of Clinical Investigation 79, 1713-1719. 